\title{
Sobre la sección de Formación Continuada de la SED
}

\author{
L.M. Torres, F. Neira y V. Mayoral
}

Uno de los objetivos de la SED y por tanto de su Revista, ha sido ofrecer al socio y al lector, instrumentos para la formación continuada en dolor, que contaran con el aval y la acreditación de los organismos correspondientes. Durante los pasados años la revista ha estado acreditada en su totalidad y de sus artículos se han extraído las preguntas que han constituido los test para obtener la acreditación.

La acreditación nos la otorgó la SEAFORMEC, que recientemente ha cesado en esta función, que ha sido asumida por el Ministerio de Sanidad, y nos ha comunicado un cambio en los procedimientos de acreditación para las revistas médicas, de tal modo que ya no se acreditan revistas sino artículos, que tienen que ser enviados con mucha antelación.

Actualmente estamos intentando cambiar nuestro procedimiento de producción para poder ajustarnos en el tiempo que nos exigen, lo cual no es fácil dado los requisitos que nos exigen. Por ello hasta entonces la sección queda en suspenso.

Cuando podamos adaptarnos a las exigencias de la agencia lo comunicaremos y reanudaremos la sección.

Gracias a todos los que colaboráis y participáis en esta sección de la RESED

LM Torres. Director de la RESED

F. Neira. Coordinador de la Sección de Formación Continuada

V. Mayoral. Secretario de la SED 